\title{
Fermilab
}

TM-1346

2750.000

TEST RESULTS AND DESIGN DETAILS

OF THE TOHOKU BUBBLE CHAMBER MAGNET*

W. Craddock and C. Grozis

Fermi National Accelerator Laboratory, Batavia, Illinois

M. Mruzek

KMS Fusion, Ann Arbor, Michigan

September 1985

*Presented at the 1985 Cryogenic Engineering Conference and International Cryogenic Materials Conference, Massachusetts Institute of Technology, Cambridge, Massachusetts, August 12-16, 1985. 
TEST RESULTS AND DESIGN DETAILS OF THE TOHOKU BUBBLE CHAMBER MAGNET

\author{
W. Craddock and C. Groz1s \\ Fermi NatIonal Accelerator Laboratory \\ Batav1a, Illinois \\ M. Mruzek \\ KMS Fusion \\ Ann Arbor, Michigan
}

ABSTRACT

Fermilab has successfully tested an Iron bound 3 Tesla superconducting solenold for the Tohoku Bubble Chamber. Thermal performance, magnetic llelds, charging characteristics, and a special Ni30\%Fe dump resistor are reported. Low heat leak is obtained by thermally intercepting the supports with bollope gas.

\title{
INTRODUCTION
}

A superconducting split solenold for Fermllab's holographic freon Tohoku Bubble Chamber has been bullt and successfully tested to its design current. This magnet was originally intended for the 30-inch Bubble Chamber as part of an energy conservation program, but the iron and vacuum shell were modifled during construction to accommodate the new larger chamber.

\section{DESIGN AND CONSTRUCTION}

The Iron bound magnet is layer wound with a solder pilled cable on periodic G-10 spacers which provide electrical insulation and cooling channels. Two vertical, gravity leed pool bolling colls have independent cryogenlc/vacuum systems which can be moved apart cold with their iron halves for quick maintenance of the chamber. The support system consists of 8 axial and 4 horizontal flberglass compression posts, 16 Inconel 718 axial preload rods, and 2 vertical stainless steel tension 1inks. Each support has $a \mathrm{LN}_{2}$ and a hellum bollofl gas intercept. Table 1 ilsts the most important parameters. See reference 1 for further construction and assembly detalis. Figure, 1 is an overall isometric of one half of the system, and $\mathrm{F}_{1 \mathrm{~g} .} \cdot 2$ shows a coll cross section through one of the fiberglass epoxy supports. The vacuum shell is five sided to provide clearance to the close fitting bubble chamber.

As part of Fermilab's Increasingly tight safety standards and review procedures, extensive inite element analysis was performed using ANSYS 


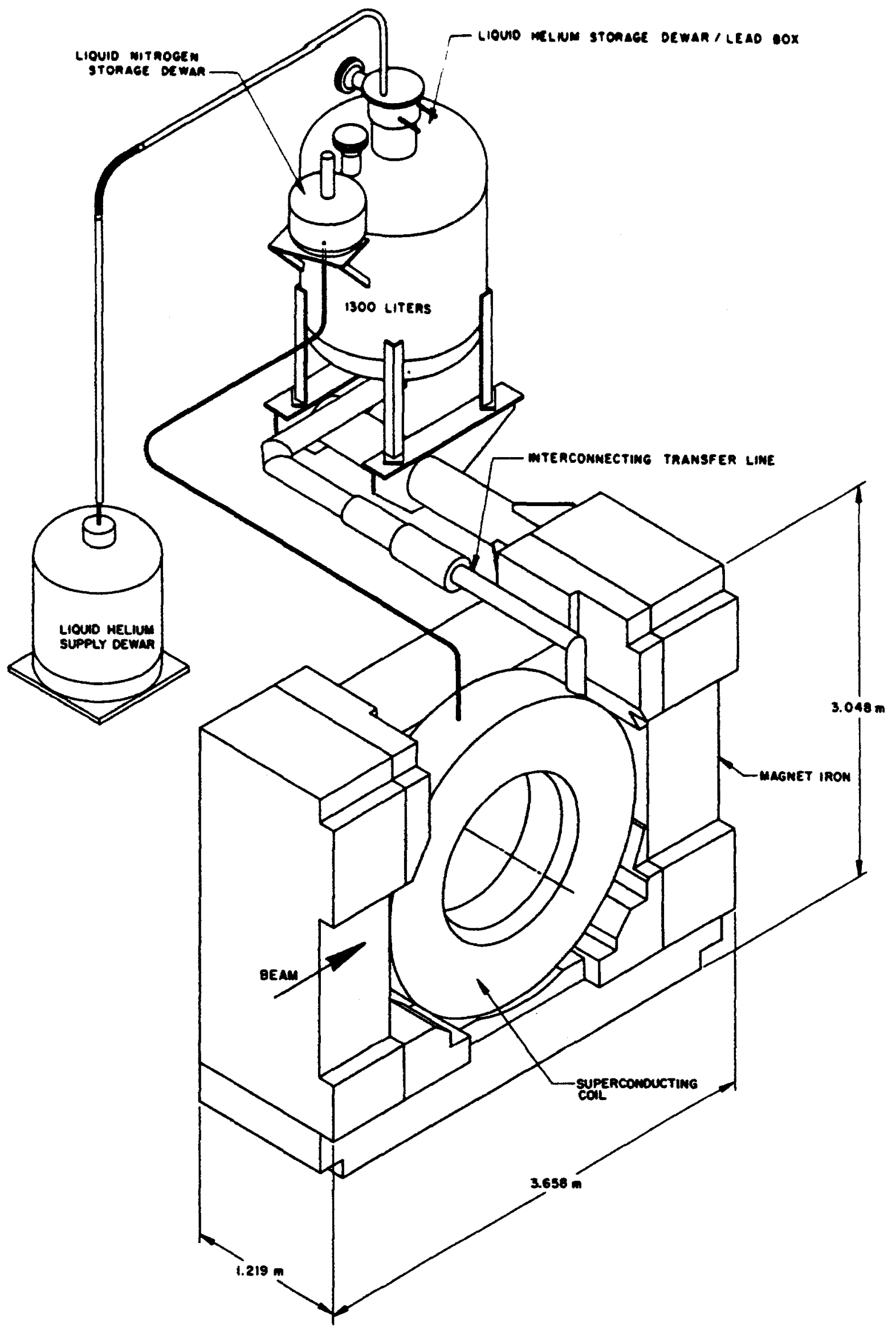

Fig. 1. One half the magnet system. 
Conflguration:

Central pleld:

Clear Bore:

Stored Energy :

Amp Turns:

Operating Current:

Inductance :

Winding I.D.:

Winding $0: D$ : :

Maximum Field on Conductor:

Overall Conductor Dimension:

Conductor Current Density:

Co11 Current Dens1ty:

\$ Short Sample:

Conductor Heat Flux:

Number of Layers:

Copper/NbT1:

Fraction Short Sample:

Conductor heat Flux:

Max. Axlal Force per Coll

(Calculated:

Axial Magnetic Spring Constant:

Vertical Radial Decentering

Force (Measured):

Horizontal Radial Decentering

Force (Measured):

Measured Helium Bollof at 700 A:

Dump Resistor:

Welght of Magnet Iron:
Split solenold with horlzontal axis

for all major components of the magnet system. Results show design stress level compliance to Section VIII, Division 2 of the ASME Pressure Vessel Code when $4.2 \mathrm{~K}$ material properties were chosen. Cryostats, LHe dewars, $\mathrm{LN}_{2}$ dewars; and the common vacuum spaces were all pneumatically pressure tested to at least 1.25 times the maximum possible pressure. Computer analysis shows $0.6 \mathrm{MPa}$ is the maximum possible pressure in the helium system. In the event of a massive quench, the 80 liters of helium in the cryostat would be rapidly expelled up into the storage dewar resulting in a supercitical or a compressed liquid state. Coll winding would then absorb all remaining heat. Emergency vent lines are installed on only the Lhe system. Hellum bolloef gas is normally recovered by the 15 Foot Bubble Chamber Magnet.

MAGNET COOLDOWN AND THERMAL PERFORMANCE

A LN 2 precool was started on March 18, 1985. Accumulated $\mathrm{LN}_{2}$ was blown out by pressurization with the remaining traces removed by a vacuum pump. LHe cooldown as well as the $\mathrm{LN}_{3}$ cooldown both use the flexible liquid hellum transfer line shown in Fig. 1. Due to its unwelldy 12 meter length, this line remains in the storage: dewar at all times. For cooldown the liquid hellum transfer line is seated in a polished cone at the bottom of the storage dewar. This is connected to a small line running to the very bottom of the magnet for efflcient cooling. At all other times the transfer line is unseated to gravity feed LHe to the coll. Figure 3 shows this line and the overall helfum bollopf cooling scheme. 


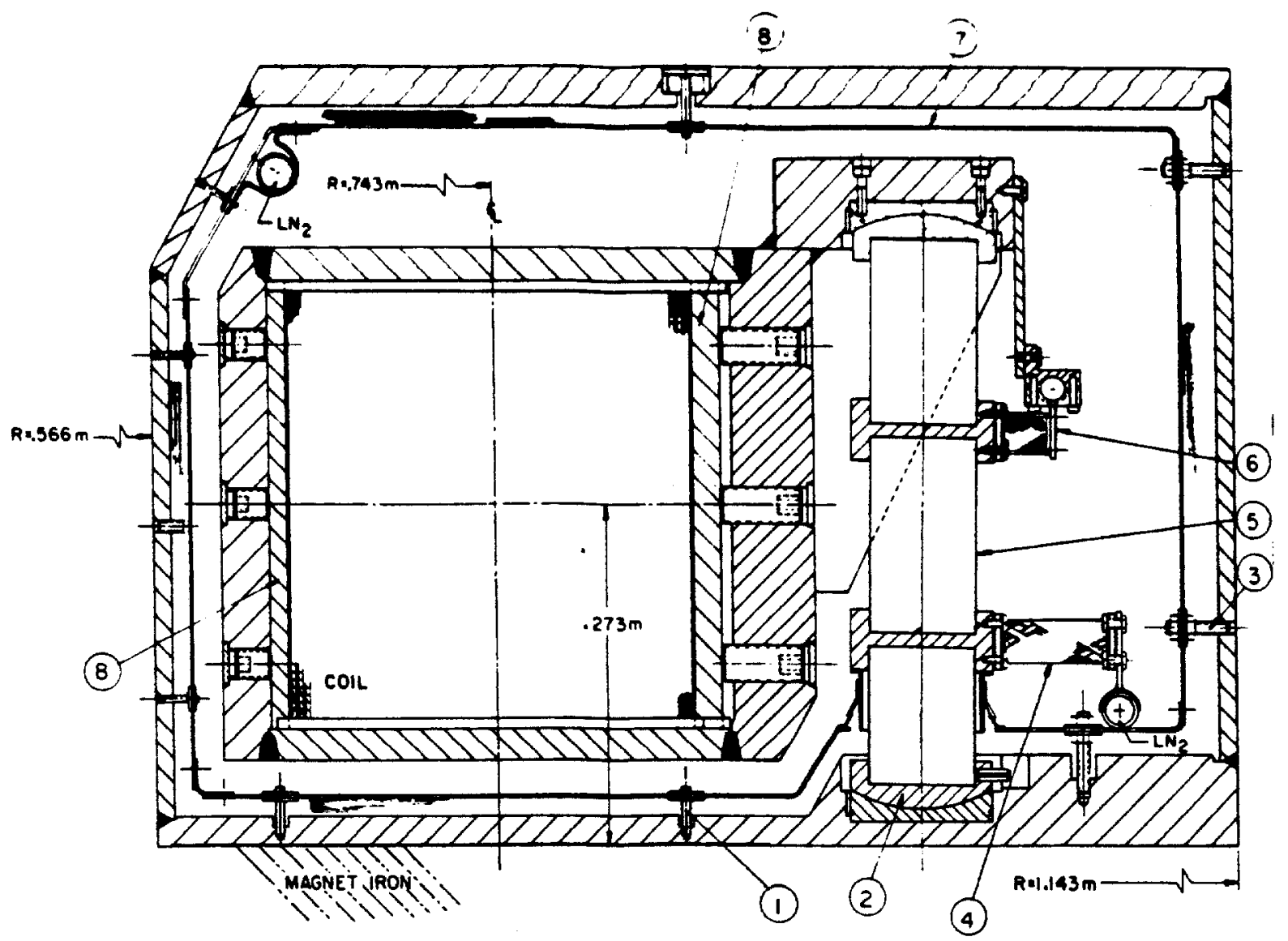

Fig. 2. Coll cross section through an axial support post. LEGEND: (1) Ti6A14V standoff; (2) 7075-T6 aluminum spherical bearing surface; (3) G-10 standoff; (4) copper braid; (5) Randolite fiberglass epoxy axial support; (6) $210 \mathrm{~K}$ He gas intercept; (7) $\mathrm{LN}_{2}$ shield; (8) coll preload bars.

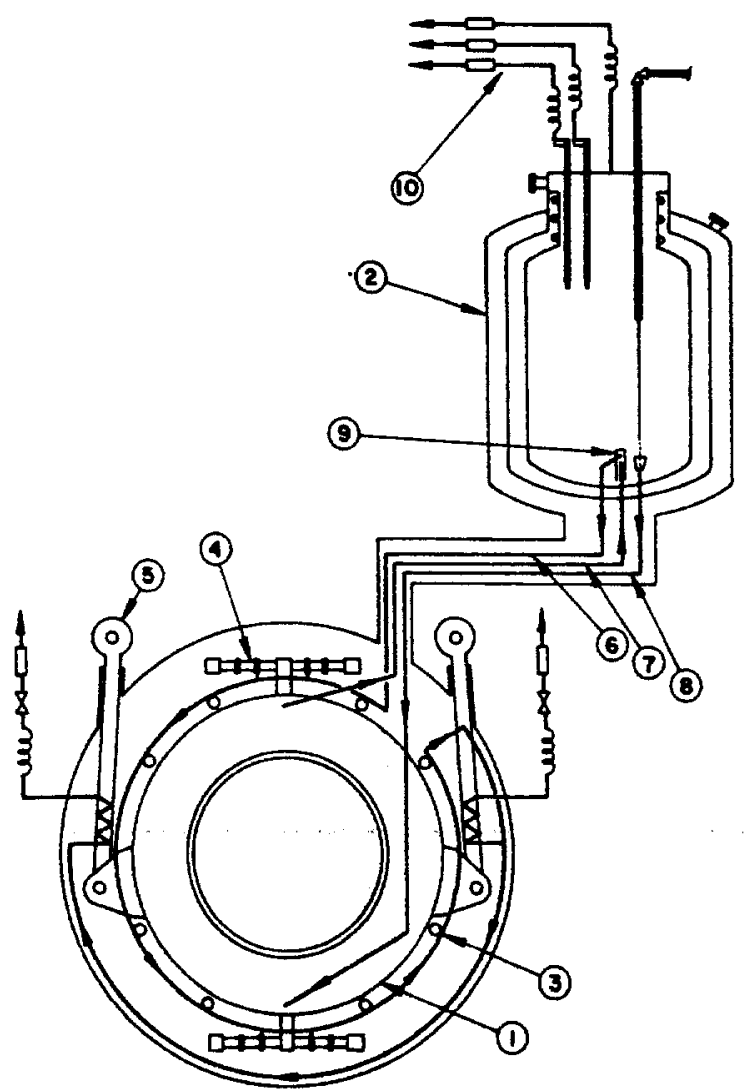

Fig. 3. Helium flow schematic for one coil. LEGEND: (1) coil; (2) LHe storage dewar; (3) fiberglass epoxy axial support; not shown are two small Inconel 718 preload rods; (4) fiberglass horizontal support;

(5) vertical tension links; (6) helium boiloff gas to supports; (8) LHe cooldown Iine and normal supply line; (9) gas collection can; (10) hellum cooling vent lines for current leads and dewar neck. 
The support system is desigped to carry $2.2 \times 10^{6} \mathrm{~N}$ axial, $7.8 \mathrm{x}$ $10^{5} \mathrm{~N}$ vertical, and $3.3 \times 10^{5} \mathrm{~N}$ horizontal loads. As shown in Fig. 3 , vaporized hellum from the coll is collected in the dewar and routed back to the 12 flberglass supports in an internally inned tube. Thermal connections are made with a copper brald. After intercepting the last post, the gas stream is split between the two stainless steel vertlcal supports. The hellum flows up each member in a serpentine fashion through a serles of 38 holes which have been threaded for Improved heat transfer. Large forces and 11ttle avallable room for support members necessitated using this complex cooling scheme.

Within construction constraints all helium intercepts for axial/horizontal supports are placed at their optimum location. An energy balance for self-sufficlent mass flow gives the following results ${ }^{2}$.

$r=Q_{1} / Q_{0}=\frac{1+C(T-4.2) B}{1+C(T-4.2)}=\frac{\text { heat from a self-sufficlent cooled support }}{\text { heat from an uncooled support }}$

$$
l_{1} / L=\frac{l_{1}}{l_{1}+l_{2}}=B / Y
$$

where

$$
\begin{aligned}
& Q_{1}=\frac{A}{l_{1}} \int_{4.2}^{T} K(T) d T \quad ; \quad Q_{2}=\frac{A}{\ell_{2}} \int_{T}^{T_{L N 2}}(T) d t ; \quad Q_{0}=\frac{A}{L} \int_{4.2}^{T(T) d t} \\
& \ell_{1}=\text { length between } 4.2 \text { and the intercept at temperature } T \\
& \ell_{2}=\text { length between } T \text { and the } \mathrm{LN}_{2} \text { intercept at temperature } T_{\mathrm{LN} 2} \\
& A=\text { area of the support } \\
& C=C_{p} / \Delta h_{v} \\
& B=\int_{4.2}^{T} K(T) d T, \int_{4.2}^{T} K(T) d T
\end{aligned}
$$

To $P$ ind the optimum location and heat leak, plot $\gamma$ and $l_{1} / L$ versus $T$. With a self-sufficient 1 low these supports have a heat leak of 1.15 watts per coll which is only $22 \%$ of an uncooled system. Heat leak other than for self-sufficlent mass flow can also be calculated with an energy balance. When the bollopf gas from other heat sources is added to the intercept stream there is an overall reduction in the heat load. For external heat loads up to the size of the self-sufficient support heat load, -0.55 watts are generated per watt of external heat. Any metallic or nonmetallc support optimized near the self-sufficient point should have similar performance.

Both the vertical tension links and the dewar neck are cooled in a continuous fashion with bolloff gas ${ }^{3}$. The self-sufficlent heat leak for these supports is 1.16 watts per coll, only $9 \%$ the heat leak of the uncooled case. A minimum $4.2 \mathrm{~K}$ heat load of 0.56 watts is found due to the $\rho$ inite distance between $4.2 \mathrm{~K}$ and the start of the $15 \mathrm{~K}$ gas leaving the axial/horizontal supports: 
Totaling all heat loads at 700 Amps for the entire magnet gives:

14 watts - 2011 ter/hr ( $4.2 \mathrm{~K}$, all supports self sufficlent)

10 watts - 1411 ter $/ \mathrm{hr}(4.2 \mathrm{~K}$, theoretical minimum)

13 watts $=1811$ ter $/ \mathrm{hr}$ ( $4.2 \mathrm{~K}$, measured heat leak based on 11quid level rather than generated gas)

52 watts $=74$ 11ter/hr ( $4.2 \mathrm{~K}$, no gas cool1ng)

790 watts - 1811 ter $/ \mathrm{hr}$ (calculated $\mathrm{LN}_{2}$ neat load)

1030 watts - 2311 ter/hr (measured $L_{2}$ bolloff rate)

Two pair of current leads contribute 4.2 watts or $1 / 3$ of the $4.2 \mathrm{~K}$ heat load. $\mathrm{LN}_{2}$ intercepts were measured at $100 \mathrm{~K}$ 'with the remainder of the $L_{2}$ shleld at $90 \mathrm{~K}$. A thermal syphon technlque relying on bouancy difference circulates the $\mathrm{LN}_{2}$. The small dewar in Fig. 1 leeds $\mathrm{LN}_{2}$ to the bottom of the magnet in an insulated line. The return pipe back to the dewar intercepts all the supports and radiation including those in the Lhe dewar shield. There is no easy method to measure this llow rate.

\section{MAGNETIC FIELD CALCULATIONS AND TEST RESULTS}

The magnetic ileld was calculated with cylindrical symmetry using TRIM. Compare the Iron model in the Fig. 4 flux plot with the actual iron shape in Fig. 1. Magnetic flelds, axial forces, and decentering forces were all measured. At full current, 700 Amps, the measured central ileld of $2.89 \mathrm{~T}$ is only 18 greater than the calculated value. Magnetic forces are listed in Table 1. Rellable measured axial forces are not avallable due to instrumentation problems, although both measured and calculated axlal force maximums occur very near 600 Amps. Vertical forces are much smaller than the design value since large air gaps for muons were machined off the bottom of the iron for the new experiment. Both downstream vertical supports have six times the load of the upstream supports. Lack of Iron symmetry across the vertical midplane is the most probable cause.

The magnet was tested to full current on April 16, 1985 by successively ramping and discharging in increasing -100 Amp increments.

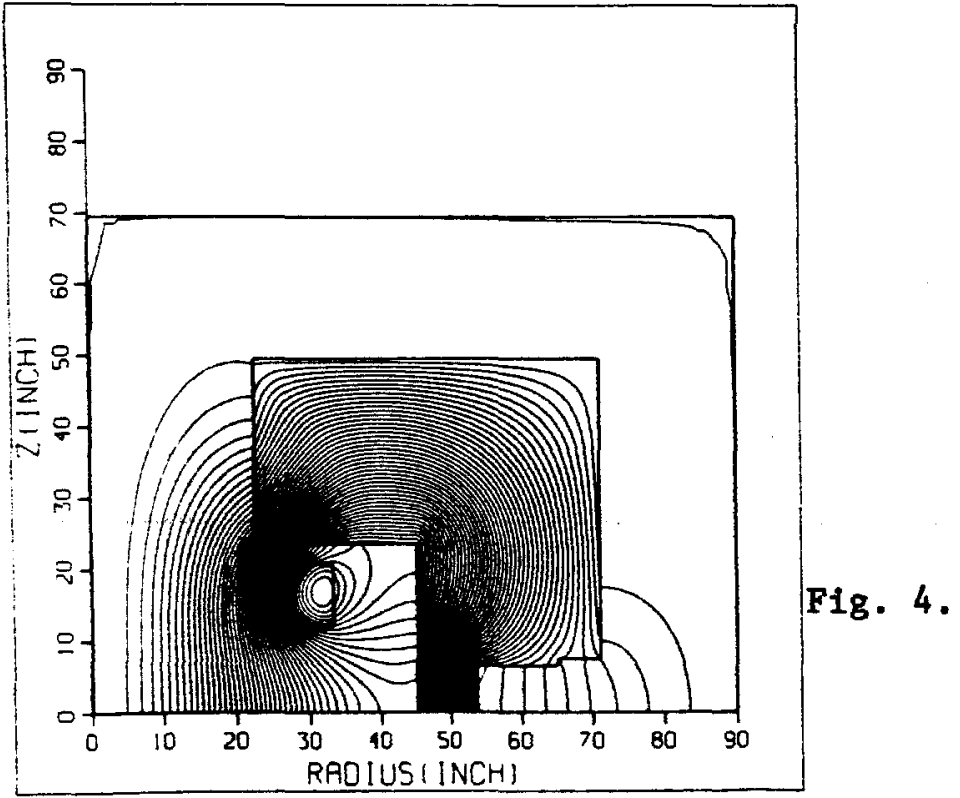

TRIM magnetic flux line plot. Air gap areas and distances at the midplane of this model equal the air gaps shown in Fig. 1. 
Voltage Imbalance between the colls whlch functlons as the quench detector was continuously recorded during testing. A condensed voltage Imbalance history shown in F18. 5 clearly shows larger voltage spikes as a function of higher current. This curve is a composite of typlcal signals seen in each 50 Amp increment. Total charge time is 32 minutes. Voltage spikes correspond to small translents created as the windings shlft. In the 300 to 600 Amp range audible "pinglng" was clearly heard simultaneously with the voltage spikes. A $64 \mathrm{mV}$ peak was the largest recorded. The Chlcago Cyclotron Magnet was bullt with identical cable and had similar electrical behavior except that its largest voltage splkes were on the order of several volts". The Tohoku Bubble Chamber Magnet is thought to have much greater radial preload and tighter coll package; therefore, smaller conductor motions should be possible.

From 600 to 700 Amps very little acoustical and electrical nolse were present. Interestingly, 600 Amps corresponds to exactly the peak in the axial force. Radial compression of these windings were excellent, but axial preload was done by hand with small shims and 1 s far from perfect. The conductors were bonded to the interlayer spacers with epoxy. One can conclude voltage spikes caused by axlal conductor motion would be present in any magnet of similar construction.

On subsequent ramps virtually no voltage spikes are present except those induced by the pulsing of the chamber which are on the order of $15 \mathrm{mV}$. Inductance between the two halves is matched very precisely, and only a $20 \mathrm{mV}$ imbalance shlft occurs between 0 and 700 Amps. If Iron and colls halves were not nearly identical, our $50 \mathrm{mV}$ quench trip level would have been difflcult to achleve.

Magnet stability is maintained by operating below the cold end recovery current. No quenches have occurred, but the energy could be safely removed during a quench with the dump resistor used for normal discharge. This resistor is specially designed with a $70 \% \mathrm{N1} 308 \mathrm{Fe}$ alloy having a large coefficlent of resistivity. Instead of an exponential decay, the resistor/magnet combination roughly approximates a constant voltage decay. Using this technique permits a lower maximum discharge voltage for a given maximum adiabatic hot spot temperature calculated from

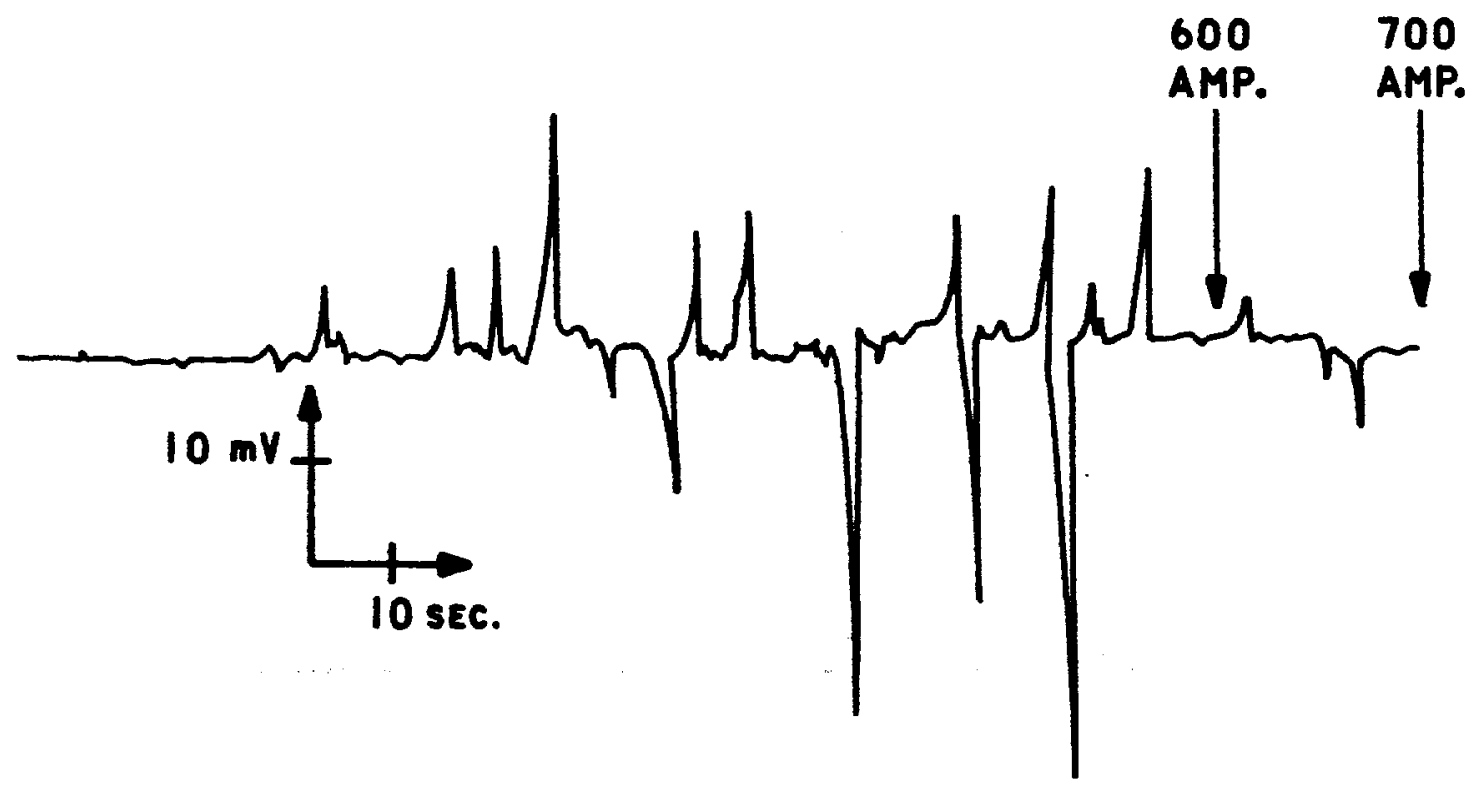

Fig. 5. A condensed voltage record during the first charge to 700 Amps. For each $50 \mathrm{Amp}$ increment a typical signal was selected. 


$$
\int_{0}^{\infty} I^{2} d t=\int_{293}^{T} \frac{C_{p}(T)}{R(T)} d t
$$

At 710 Amps the hot spot temperature 1 s calculated to be $265 \mathrm{~K}$. A 650 Volt maximum appears -10 seconds into the discharge. If a resistor with constant value were used, a 900 Volt discharge would have been necessary for the same 1 imlting conductor temperature. A perfect constant voltage discharge has only $2 / 3$ the peak voltage of an exponential discharge. Our magnet/resistor comes close to this theoretical ilmit.

\section{REFERENCES}

1. W. Craddock et al, Coll Conversion of the Fermilab 30-Inch Bubble Chamber Magnet, in: "Advances in Cryogenic Engineering", Vol. 27, Plenum Press, New York (1982), p. 119.

2. I. Pless and T. Stoughton, "FHS Magnet Technlcal Memo No. 1", Private Communication, (1979):

3. R. B. Scott, "Cryogenic Engineering", Van Nostrand, Princeton, N.J., (1967), p. 239.

4. E. Leung et al, The Superconducting Chicago Cyclotron Magnet, in, "Advances in Cryogenic Engineering," Vol. 27, Plenum Press, New York (1982), p. 135. 